\title{
Maintaining Harmony of Life in Skipped-Generation Households of the Older Adults
}

\section{Patcharee Komjakraphan $^{1}$ and Wannee Chansawang ${ }^{1}$}

\begin{abstract}
This phenomenological study explored the experiences of Thai grandparents who were raising their grandchildren in the absence of their parents. Semi-structured interviews were conducted among 17 grandparents representing 11 families. Data analysis identified the emerging themes of maintaining harmony of life, including perspective of life, positive frame of mind, courage and hope, intrinsic motivation, and perception toward the new role. The results of this study can contribute to enhancing the harmony of life for grandparents raising their grandchildren in skipped-generation households.
\end{abstract}

Keywords

maintaining harmony, skipped-generation households, phenomenology, Thai grandparents

\section{Introduction}

Skipped-generation households are families in which grandparents raise children and parents are absent from the household (Rothausen-Vange, 2005). Around the year 2000, nearly $30 \%$ of the older population in the developing countries lived in skipped-generation households (United Nations, 2011). This living arrangement has been attributed to societal trends, such as drug abuse, teen pregnancy, divorce, singleparent households, mental and physical illness, and AIDS (Winokur, Holtan, \& Valentine, 2009). Increasing number of skipped-generation households is an important phenomenon and it is an important household type that cannot be ignored. The impact of the living arrangement may be particularly acute for older adults. They are impacted across many issues, from intrapersonal health concerns to policy decisions that affect their services (Shakya, Usita, Eisenberg, Weston, \& Liles, 2012).

The older adults living in skipped-generation households are vulnerable to depression and social isolation (Bryson, 1999; Minkler et al., 1997). These problems challenge their sense of self and capacity to live happily. However, it is found that optimism can reduce levels of stress and depression and promote health, by counteracting stress (Brissette, Scheier, \& Carver, 2002; Brydon, Walker, Wawrzyniak, Chart, \& Steptoe, 2009). Optimism is a key contributor to subjective well-being because it fosters self-esteem and relationship harmony (Leung, Moneta, \& McBride-Chang,
2005). In addition, it was found that a well-being is significantly determined by a harmonious relationship with others (Yap \& Tan, 2011).

Harmony is usually identified as a human value, referring to compatibility and accord in feelings, actions, relationships, opinions, and interests. Easley's (2007) concept analysis identified the attributes of harmony as peace, balance, and rhythm. Those events or incidents that occur as a result of harmony are a pleasant environment, a sense or feeling of satisfaction or achievement, or a positive self-concept (Easley, 2007). The notion of harmony can be traced back to Confucianism and Taoism in East Asia. Lao Tzu, an ancient Chinese philosopher, advocated living in harmony with nature to achieve balance and inner peace of mind. The Confucian classics also emphasized harmony as a guiding principle in interpersonal relationships and social roles, as it is essential to the stability of families and prosperity of human societies (Lopez, 2009).

In Thailand, the number of Thai older adult living in skipped-generation households has been increasing. The proportion of older adults who live in skipped-generation households increased from $10.5 \%$ in 1994 to $14.3 \%$ in 2007 (Knodel \& Chayovan, 2009). Addressing the issues affecting harmony of life in skipped-generation households is important because living in harmony may reduce levels of stress and depression.

\footnotetext{
${ }^{1}$ Prince of Songkla University, Hat Yai, Thailand

Corresponding Author:

Patcharee Komjakraphan, Prince of Songkla University, 15

Kanchanavanich Rd., Hat Yai, 90112, Thailand.

Email: patcharee.ko@psu.ac.th
} 


\section{Purpose of Study}

The purposes of this study are to understand the experience of Thai grandparents while raising their grandchildren in the absence of the children's parents and to understand how the grandparents maintain harmony of life.

\section{Objectives}

The study aims to use Husserlian phenomenological approach to explore and explain the harmony of life in which Thai grandparents who reside with their grandchildren in skippedgeneration households make sense of, or derive an understanding from, their role as parents for their grandchildren.

\section{Method}

The researchers adopted a Husserlian phenomenological research design to proceed inductively and to derive meanings from human experience through the use of the phenomenological approach. Husserl believed in phenomenological reduction - that reflection on existing beliefs helps obtaining unadulterated phenomena that would otherwise be unobtainable. Husserlian's phenomenological studies "uncovered and described the fundamental structure of our life world" (Cohen \& Omery, 1994). In addition, his phenomenology emphasizes description of a person's live experience. This is a descriptive study investigating the lived experience of Thai grandparents who were raising their grandchildren in the absence of their parents. Husserlian phenomenology, because of its descriptive orientation, is best-suited for this purpose.

\section{Selection of the Sample and Data Collection}

To recruit participants from a large community, letters and study information sheets were sent to the heads of the three health centers located in the same province in Southern Thailand. Health centers provide integrated health services to the people in their designated areas. A health center is generally operated by a health worker and a professional nurse using village heath care volunteers as the main facilitator and health disseminator. After they were informed about the purpose and details of the research, the health care volunteers introduced the principle investigator (PI) to the grandparents who met the inclusion criteria of the study and agreed to participate.

A convenient and purposive sample of 11 skippedgenerations households in Songkhla province was selected. A purposive sampling technique was used to recruit the participants. To select "information rich" cases for in-depth study, grandparents of any age, gender, cultural background, or socio-economic group were eligible. Inclusion criteria required that the grandparents resided with their grandchildren in skipped-generation households for at least
Table 1. Demographic Data for Participants Included in the Study $(N=17)$.

\begin{tabular}{ll}
\hline Demographic & $N(\%)$ \\
\hline Gender & $11(64.7)$ \\
Male & $6(35.2)$ \\
Female & \\
Age & $14(82.3)$ \\
60-69 years & $2(11.7)$ \\
$70-79$ years & $1(5.8)$ \\
80 or above & \\
Work status & $4(23.5)$ \\
Unemployed & $12(70.7)$ \\
Employed & $1(5.8)$ \\
Not in labor force & $17(100)$ \\
Religion & \\
Buddhism & $12(70.5)$ \\
Marital status & $5(29.4)$ \\
Married & \\
Separated/divorced & $10(58.8)$ \\
Perceived health status & $4(23.5)$ \\
Healthy & $3(17.6)$ \\
Fair &
\end{tabular}

Table 2. Living Arrangement of the Participant Included in the Study $(n=11)$.

\begin{tabular}{ll}
\hline Living arrangement & $\mathrm{n}(\%)$ \\
\hline Size of household & $1(9.09)$ \\
2 people & $9(81.8)$ \\
3 people & $1(9.09)$ \\
4 people & \\
Co-residing & $1(9.09)$ \\
$\quad$ Grandfather/mother only living with & \\
$\quad$ one child & \\
$\quad$ Grandfather/mother only living with & \\
more than one child & $4(36.3)$ \\
$\quad$ Grandparents living with one child & $1(9.09)$ \\
Household area & \\
$\quad$ Urban area & $3(27.2)$ \\
Rural area & $8(72.7)$ \\
\hline
\end{tabular}

1 year prior to the interview and were willing to participate. A total of 17 grandparents took part in the study. The par- ticipants were drawn from a range of urban $(n=3)$ and rural $(n=8)$ areas of Songkla province. The grandparents ranged in age from their late 60 s to mid-80s and were from a diver- sity of socio-economic and cultural backgrounds. After receiving an elder's consent to participate, the PI arranged a date and time to meet in his or her home to obtain demo- graphic information and conduct an in-depth interview. The majority of participants and their living arrangement were presented in Tables 1 and 2. 


\section{Data Collection}

Data were collected from 17 participants. Guiding questions were used to bracket the research topic and acted as a deterrent from collecting data that might have been useless in describing the phenomenon (Miles \& Huberman, 1994; Moustakas, 1994). Once written consent was obtained, the interviews proceeded with the aim of obtaining a description of Thai grandparents' experience in raising their grandchildren in the absence of the children's parents. Semistructured, face-to-face interviews were conducted using a pre-prepared interview guide. Participants were encouraged to talk freely and to tell stories using their own words. Examples of questions or statements posed to the grandparents included the following: "Why do you become parents to your grandchild/children all over again?" "What do you do to take care of your grandchild/children?" "How do you feel about your daily life?" "How about raising your grandchild/children?" "What do you think about living in harmony?" and "Exactly what do you do to overcome all the problems?" Probing questions and statements also were posed to obtain more in-depth data and clarify understanding of each elder's comments. Examples of probing statements used included the following: "Tell me more about how do you do to overcome your stress," "Please tell me more about the reasons that lead you to think or act like that." During each interview, the PI also engaged in observation of the respective participant's non-verbal behavior, interactions of family members with the participants. Field notes of all observations were recorded. The data gathering process lasted approximately from $45 \mathrm{~min}$ to $1 \mathrm{hr}$. Each participant was interviewed once or twice, and all of them were conducted by the PI. Audio recording was used to record each interview and was later transcribed verbatim after each interview. A follow-up contact enabled clarification and validation. The interviews were conducted over a period of 6 months, from June 2011 to November 2011. A semi-structured interview format was used to gather contextual descriptions to uncover truth revealed through reflection of the experiences (Morse, 1994).

\section{Ethical Considerations}

Formal ethical approval of this study was obtained from the Ethics Committee at Faculty of Nursing, the Prince of Songkla University, Thailand, prior to conducting the study. Permission to record the interviews was obtained from the participants, and an inform consent form was discussed and signed before the interview began. In addition, the participants were informed that they could withdraw from the study at any time without penalty. To provide confidentiality and anonymity of the participants, the participants were informed that information they provide will be treated confidentially and, if published, will not be identifiable as theirs.

\section{Data Analysis}

The method of analysis described by Colaizzi (1978) was utilized to provide a rich description of the essential structure of the phenomena. Colaizzi developed his approach from the Husserlian School (Cohen \& Omery, 1994), and his method is frequently utilized in phenomenological research. It is well-suited to Husserlian phenomenology as Husserlian descriptive principles underpin his method of analysis (Koch, 1995). The steps were used and confirmed by two researchers as follows:

1. Each transcript was read several times to gain a sense of the whole content. During this stage, any thoughts, feelings, and ideas that arose by the researcher were added to the bracketing diary. This helped to explore the phenomenon as experienced by participants themselves.

2. Significant statements that pertain to the phenomenon under study should be extracted. In this stage, significant statements and phrases pertaining to maintaining harmony of life were extracted from each transcript. These statements were written in separate sheets and coded based on their "transcript, page, and line numbers." After extracting the significant statements from transcripts, the two researchers compared their work and reached consensus.

3. Meanings were formulated from the significant statements. Each underlying meaning was coded in one category as they reflect an exhaustive description. Similarly, both researchers compared the formulated meanings with the original meanings maintaining the consistency of descriptions.

4. The formulated meanings should be sorted into categories, clusters of themes, and themes. This stage involved grouping the formulated meanings into categories and initiated structure of clusters of themes. Each cluster of theme was coded to include all formulated meanings related to that group of meanings. After that, groups of clusters of themes that reflect a particular vision issue were incorporated together to form a distinctive construct of theme. Indeed, all these themes are internally convergent and externally divergent; meaning that each "formulated meaning" falls only in one theme cluster that is distinguished in meaning from other structures. Later, both researchers compared their clusters of themes and checked the accuracy of the overall thematic map along with having assistance from the expert researcher in qualitative research.

5. The findings of the study should be integrated into an exhaustive description of the phenomenon under study. At this stage of analysis, all emergent themes were defined into an exhaustive description. After merging all study themes, the whole structure of the 
phenomenon "maintaining harmony of life" has been extracted. Finally, a validation to this exhaustive description was confirmed among the researchers.

6. The fundamental structure of the phenomenon should be described. This step is similar to the previous step, but no exhaustive meanings were sought. In this step, a reduction of findings was done in which redundant, misused, or overestimated descriptions were eradicated from the overall structure. It seems that such an attempt was made to emphasize on the fundamental structure. Some amendments were applied to generate clear relationships between clusters of theme and their extracted themes, which included also eliminating some ambiguous structures that weaken the whole description.

7. Finally, validation of the findings should be sought from the research participants to compare the researcher's descriptive results with their experiences. This step aimed to validate study findings using "member checking" technique. It was undertaken through returning the research findings to the participants and discussing the results with them. Eventually, all participants showed their satisfaction toward these results that entirely reflect their feelings and experiences. Finally, validation of the findings should be sought from the research participants to compare the researcher's descriptive results with their experiences.

Triangulation was used to ensure the integrity and accuracy of the findings (Patton, 1990). According to Rossman and Rallis (2003), triangulation is a method for looking at data in a different way or from a different point of view. Investigator triangulation involves using several different investigators in the analysis process. This step was accomplished by recruiting two nurse educators, who had expertise in qualitative research to serve as evaluators and to read the transcripts and assisted with data analysis with the PI. After a time of reflection, the triangulating analysts met with the PI to compare findings and validate emerging themes, make corrections, and elicit additional information about the phenomenon. For example, when differences were found between the researchers, the whole statements and their meanings were checked by an expert researcher who found the process is correct and the meanings are consistent and had agreement on the final forms of the findings.

\section{Results}

In this study, the researchers gained an understanding of what harmony of life experienced and how harmony of life was developed. Data analysis revealed that the grandparents are experiencing many difficulties toward their daily life. However, they used several positive coping strategies to maintain their harmony of life. Positive coping strategies that influenced positive feelings toward the grandparent's daily life involved several issues. They learn to think positively even when things go wrong as their perspective of life, frame of mind, and courage and hope. Other strategies were intrinsic motivation such as feelings of unconditional love and a sense of family responsibility and commitment. The perceptions toward their new role also influenced harmony of life among the grandparents.

\section{Maintaining Harmony of Life}

Maintaining harmony of life was identified as the grandparents' positive feelings toward their daily life with their grandchildren in the absence of the children's parents. These feelings were described as pleasant feelings of happiness and feelings of balance, tolerance, and understanding. The participants described these feelings as "compatibility with daily life."

Having my two grandchildren with me I don't have to worry about their well-being; they are safe with me. I'm thankful every day that I was given the chance to give my grandchildren a better life. (K12)

I have nothing to worry about. I can go out anywhere with my grandson. Whenever they ask me to attend the school events, I'll go. He is not a problem at all. (K10)

Even though I live my life the way I don't want to, everything is fine with me. I have no problem with anything. Everything in my life is basically the same as usual and I can live like this. I do the dishes, mop all the house, and do all the laundry. My grandson came to live with me when he was three months old. I spent most of my time catering to him, running him around, and entertaining him. It was all about my grandson. (K8)

I do what I have to do. He knows that he can rely on my time, my presence, and my interest. Those are my responsibility. You should be glad that you have a house to clean, dishes to clean, a grandson to raise. (K5)

The decision for us to adopt my great-grandson has given us stability and a feeling of permanence in our situation. My greatgrandson calls us "Mom" and "Dad" and he feels more secure in knowing we will always be here and no one can come in and upset the life he has. (K17)

Perspective of life. The participants shared similar experiences within the theme "perspective of life." Taking on responsibility of raising grandchildren without their parents is not easy. Most of them were faced with a myriad of daily, weekly, and monthly obstacles that must be negotiated and managed on behalf of their grandchildren. However, they simply accepted everything that happened in their life as expressed in the following statements:

I feel like there is no opportunity to have fun with my friends anymore. May be it's time to stop hanging around but staying home and raising grandkids ... too old ... I guess. (K1) 
I suppose my life can't get any better than this. It is notpossible to expect more, right? What should I be looking for? . . . going to the temple, making a merit ... that's all. (K13)

Positive frame of mind. The participants expressed their feel- ings related to life as they preferred it at that moment. Although their lives were tough, their views were so positive, as evidenced in the following statements:

Don't look at the rich . . . don't do it. I'm happy with my old bike. I knew someone who didn't have any money and had so much debt, but she still borrowed more just to buy a new suit ... I don't like it. (K2)

My life has always been unpredictable, but I survived through it all, even the hardest times in my life ... I always think about that $\ldots(\mathrm{K} 5)$

The data showed that the participants looked at things with an upbeat and positive perspective. Having a positive frame of mind influenced the participants' feelings toward their lives. Being in harmony with their surroundings thus requires a positive frame of mind.

Courage and hope. Most of the participants stepped in during a family crisis such as divorce or death of parents to rear their grandchildren. They summoned courage in their own lives in many different ways to be harmonious with their new role. Most of the participants had become more determined because their conscience simply would not allow them to ignore what was happening around them. In adverse events, they deliberately chose to be strong. For instance, they exchanged their freedom for a burden.

It's OK, but it's not fun and quite difficult to go out like every time before. I enjoy going to several social events like ordination and wedding ceremonies but now I can't go out anywhere. I have to stay home all day, have never seen any day light since he was born. (K1)

As most of the families headed by grandparents were living on low income or at a poverty level, financial aid was important for them. The participants expressed their thoughts to overcome any obstacles in life such as poverty. They worked very hard and made many sacrifices to survive. For example, a participant stated,

I'll do it. No matter what, I keep at it. Even if I am the only one working, I'll keep on working. I never get scared or discouraged. Unlike most of my kids who avoid working I work at the rubber farm till 11 o'clock, come back home for lunch just one hour then go to the farm again. I've been working like that every day. (K8)

Hope was also found in participants who admitted failure in raising their own children and wanted to make it up with their grandchildren, as expressed in the following extracts:
All my children are upset with me. I have only one last chance. I want (my grandson) to be a good man and become a teacher. I wouldn't want him to be in his father's shoes. (K11)

From the positive psychology perspective, knowing our strength and using them in relationships and to service others is to acquire a good life (Seligman, 2002). Having hope in times like these will lead to happiness and success. If they have no hope in life, there will be no drive for anything and nothing will matter.

Intrinsic motivation. The grandparents were motivated to raise their grandchildren because they cared and wanted to do all that was necessary to provide a nurturing and safe home environment for their grandchildren. When the parents could not care for their children and opted to pay strangers to pro- vide care, grandparents would step in and assumed a perma- nent parental role in this situation. A grandparent is motivated by feelings of unconditional love that are combined with a deep rooted sense of family responsibility and commitment. These motivational factors increased the grandparents' vitality and zest for life, made them feel connected to their grandchildren and provided a second chance to raise their grandchildren better than they did with their own children.

I'm ok with it . . living with my grandkid like this makes me feel so much closer to him. (K16)

My life is so blessed. My granddaughter is a joy, she makes me feel young and laugh all the time. I'm thankful every day that I was given the chance to give my granddaughter a better life. (K4)

Sometimes I feel too old to raise an 11-year-old and 15-year-old. Other times they make me feel young. I am so glad I have them in my life and my home. (K9)

I hug him and take him to bed every night. We sleep together in the same bed. He asks me to read or tell stories till he falls asleep. (K6)

Perceptions toward a new role. All of the participants accepted the primary responsibility for their grandchildren and took on a parental role. Most of the participants experienced mixed feelings about raising their grandchildren. They expressed their perceptions toward their new role as being unprepared, unwilling to take on this role, and feeling burdened.

Raising (grand) children today is so much more difficult than raising my own kids. If something goes wrong, she (daughter) blames me. I have to look after him all by myself. If he were my own kid, I would find someone to take care of him from time to time when I get too busy. (K7)

Taking care of our 4-year-old granddaughter was an unexpected event and can be a real challenge at times with both of us 
working full-time, however, we love her so much and are going to do the best we can to care for and nurture her. (K4)

I love these children dearly but I have no desire to be their parent. We sometimes feel overwhelmed with all the responsibilities to care for the children. (K14)

The perceptions toward their new role varied. Some participants embraced their new role and responded with an emotional maturity. Other participants perceived taking on a parental role late in life as a blessing and were grateful for the opportunity to form a deeper bond with their grandchildren.

As I get older, I also feel sensitive more easily than before. It would be better off if I could have treated my child the same as my grandchild. (K15)

I think I love my grandchild more than my child because he is small and needs me. My other children all are grown up. They have their own family and don't need me anymore. (K8)

The degrees of acceptance the participants experienced were closely related to whether or not they had a choice in the matter. In addition, the perceptions toward a new role as parents influenced the participants' harmony of life.

\section{Conclusion}

The grandparents' experience of maintaining harmony of life showed that the grandparents considered harmony of life reaction to be an important factor in the living in skippedgeneration household, as revealed by the descriptive categories: perspective of life, positive frame of mind, courage and hope, intrinsic motivation, and perception toward their role as parents to their grandchildren. They perceived that maintaining harmony of life played a role in positive feelings toward their daily life with their grandchildren in the absence of the children's parents.

\section{Discussion}

The study suggests several interesting insights and confirms the need for more attention to this matter. Although conclusions from this study cannot be generalized beyond the sample, the consumer of qualitative research findings should determine the degree to which they can relate to the finding from practical experiences. This study captured the live experience of 17 Thai grandparents raising their grandchildren without the continuous presence of their parents.

The grandparents described the harmony of life as "compatibility with daily life." The key themes in the process of maintaining harmony of life involved their perspective of life, positive frame of mind, courage and hope, intrinsic motivation, and perception toward their role as parents to their grandchildren. As all of the participants follow
Buddhism, Buddha's very core teaching on the concept of impermanence has been influenced the way they thought as reflected on the first themes "perspective of life." Impermanence means that everything changes and nothing remains the same in any consecutive moment (Hanh, 2004). The participants simply surrendered to obstacles and accept life as it is. Therefore, they trend to accept that nothing is permanent, and it is considered as a main condition to maintain harmony of life. This finding is consistent with previous study related to harmony in life of Thai Buddhists patients (Balthip, Petchruschatachart, Piriyakoontorn, \& Boddy, 2013). The second theme, positive frame of mind, conveys "His Majesty's Philosophy of Sufficiency Economy," which is a philosophy based on the fundamental principle of Thai culture. Sufficiency Economy aims to achieve major goals of harmony or balanced living, security, sustainability, and resilience, all of which are basic elements of happiness (Indaratna, 2007). The participants imply this philosophy as their life guidance. One out of three pillars of The Philosophy is "Moderation" which means sufficiency at a level of not doing something too little or too much at the expense of oneself or others (Indaratna, 2007). Sufficiency Economy Approach provides a mind cultivating process that is essential for maintaining harmony of life. In addition, this positive frame of mind also reflected the optimism participants' feelings toward their lives. People with a highly optimistic life orientation experience daily events in a more positive way and expect more positive outcomes than pessimists (Scheier \& Carver, 1987). Courage and hope, and intrinsic motivation, the third and fourth themes, also embedded in the participants' experiences of maintaining harmony of life. Hope and courage can produce endurance and encouragement for the individuals in the face of fear and despair. They were considered as a source of inner strength and might drive a motivation that comes from inside an individual. From the positive psychology perspective, knowing and using those strengths in our relationships and in service of others is to acquire a good life and to discover the meaning of life that constitute paths to happiness (Seligman, 2002). However, perception toward a new role, the participants' subjective feeling toward this living arrangement, altered their harmony oflife.

Harmony of life is culturally dependent on spiritual relationships and religious beliefs that encourage and are guided by Buddha's teaching and the King's Philosophy of Sufficiency Economy that drive harmony of life of Thai people. Maintaining harmony of life in skipped-generation households became a dynamic and evolving process, which was built on the grandparents' knowledge and increasing willingness to engage with the professionals' emotional responses and belief systems. These findings help to define some of the complex dynamics that have an impact on the development of partnership care and might challenge nurses practicing in the community. Community nurses should assess and understand the coping strategies of the grandparents and assist them to engage in stress-reducing practices. This is an important 
partnership to be formed in family care for grandparents in the community. It may conclude that the means to reach harmony of life is mind training basically for right understanding, right thinking, and right action. Therefore, the study findings will guide further development of family's caregiving aspects in nursing practice.

\section{Declaration of Conflicting Interests}

The author(s) declared no potential conflicts of interest with respect to the research, authorship, and/or publication of this article.

\section{Funding}

The author(s) disclosed the following financial support for the research and/or authorship of this article: This research project is supported by Prince of Songkla University. Grant no. A54151Nur5406568

\section{References}

Balthip, Q., Petchruschatachart, U., Piriyakoontorn, S., \& Boddy, J. (2013). Achieving peace and harmony in life: Thai Buddhists living with HIV/AIDS. International Journal of Nursing Practice, 19(2), 7-14.

Brissette, I., Scheier, M. F., \& Carver, C. S. (2002). The role of optimism and social network development, coping, and psychological adjustment during a life transition. Journal of Personality and Social Psychology, 82, 102-111.

Brydon, L., Walker, C., Wawrzyniak, A. J., Chart, H., \& Steptoe, A. (2009). Dispositional optimism and stress-induced changes in immunity and negative mood. Brain, Behavior, and Immunity, 23, 810-816.

Bryson, K. C. (1999). Coresident grandparents and grandchildren (Current Population Reports, Special Studies). Washington, DC: U.S. Department of Commerce.

Cohen, M., \& Omery, A. (1994). Schools of phenomenology: Implications for research. In J. Morse (Ed.), Critical issues in qualitative research methods. (pp. 136-156). Newbury Park, CA: SAGE.

Colaizzi, P. (1978). Psychological research as the phenomenologist views it. In R. Valle \& M. Kings (Eds.), Existential phenomenological alternative for psychology (pp. 48-71). New York, NY: Oxford University Press.

Easley, R. (2007). Harmony: A concept analysis. Journal of Advanced Nursing, 59, 551-556.

Hanh, T. N. (2004). The heart of the Buddha's teaching: Transforming suffering into peace, joy, and liberation. London, England: Rider Books.

Indaratna, K. (2007). Provincial economic indicators for sufficiency economy. Bangkok: Thailand Research Foundation.

Knodel, J. E., \& Chayovan, N. (2009). Intergenerational relationships and family care and support for Thai elderly. Ageing International, 33(1-4), 15-27.

Koch, T. (1995). Interpretive approaches in nursing research: The influence of Husserl and Heidegger. Journal of Advanced Nursing, 21, 827-836.
Leung, B. W., Moneta, G. B., \& McBride-Chang, C. (2005). Think positively and feel positively: Optimism and life satisfaction in late life. International Journal Aging Human Development, 61, 335-365.

Lopez, S. J. (2009). The encyclopedia of positive psychology. Blackwell Publishing. Retrieved from http://www.blackwell reference.com/public/book.html?id=g9781405161251_97814 05161251

Miles, M. B., \& Huberman, A. M. (1994). Qualitative data analysis (2nd ed.). Thousand Oaks, CA: SAGE.

Minkler, M., Fuller-Thomson, E., Miller, D., \& Driver, D. (1997). Depression in grandparents raising grandchildren: Results of a national longitudinal study. Archives of Family Medicine, 6 , 445-452.

Morse, J. M. (1994). Critical issues in qualitative research methods. Thousand Oaks, CA: SAGE.

Moustakas, C. (1994). Phenomenological research methods. Thousand Oaks, CA: SAGE.

Patton, M. Q. (1990). Qualitative evaluation and research methods (2nd ed.). Newbury Park, CA: SAGE.

Rossman, G. B., \& Rallis, R. S. (2003). Learning in the field: An introduction to qualitative research. Thousand Oaks, CA: SAGE.

Rothausen-Vange, T. J. (2005). Family diversity, a Sloan work and family encyclopedia entry. Retrieved from http://wfnetwork. bc.edu/encyclopedia_entry.php?id=1138\&; area=academics

Scheier, M. F., \& Carver, C. S. (1987). Dispositional optimism and physical well-being: The influence of generalized outcome expectancies on health. Journal of Personality, 55, 169-210.

Seligman, M. E. P. (2002). Authentic happiness: Using the new positive psychology to realize your potential for lasting fulfillment. New York, NY: Free Press.

Shakya, H. B., Usita, P. M., Eisenberg, C., Weston, J., \& Liles, S. (2012). Family well-being concerns of grandparents in skipped generation families. Journal of Gerontological Social Work, $55,39-54$.

United Nations. (2011). Current Status of the Social Situation, Well-Being, Participation in Development and Rights of Older Persons Worldwide, New York: Department of Economic and Social Affairs, Population Division.

Winokur, M., Holtan, A., \& Valentine, D. (2009). Kinship care for the safety, permanency, and well-being of children removed from the home for maltreatment. Cochrane Database of Systematic Reviews, 2009(1), Article CD006546. doi:10.1002/14651858. CD006546.pub2

Yap, P. H., \& Tan, B. H. (2011). Families' experience of harmony and disharmony in systemic psychotherapy and its effects on family life. Journal of Family Therapy, 33, 302-331.

\section{Author Biographies}

Patcharee Komjakraphan is an assistant professor of nursing, Faculty of Nursing, Prince of Songkla University, Thailand.

Wannee Chansawang is an associate professor of nursing, Faculty of Nursing, Prince of Songkla University, Thailand. 